\title{
O PROBLEMA DA LINGUAGEM E O ENSINO DA MECÂNICA QUÂNTICA NO NÍVEL MÉDIO
}

\author{
The language problem in the teaching \\ of quantum mechanics at High School level
}

Iramaia Jorge Cabral de Paulo ${ }^{1}$

Marco Antonio Moreira ${ }^{2}$

Resumo: Neste artigo, é discutida a questão básica da linguagem e da captação de significados da Mecânica Quântica (MQ) como uma questão relevante para a inserção dos seus conceitos fundamentais no Ensino Médio. Sabe-se que a linguagem é fundamental para a compreensão da ciência e a construção de conceitos científicos que, ao mesmo tempo em que são específicos, podem se generalizar no contexto da vida cotidiana. A preocupação com a linguagem configurada e utilizada pela $\mathrm{MQ}$ foi evidenciada pelos seus próprios autores. Diante do problema da relação entre a linguagem clássica e a quântica, este trabalho mostra a opção da manutenção da linguagem clássica modificando-se a lógica para tratar os fenômenos quânticos, buscando-se localizar essa opção do ponto de vista epistemológico e suas implicações para o ensino.

Palavras-chave: Linguagem. Mecânica Quântica. Ensino Médio.

\begin{abstract}
In this paper the problem of language and the grasping of meanings in quantum mechanics is discussed as a relevant subject for the teaching of basic concepts at high school level. It is well known that language is fundamental for the comprehension of science and for the construction of scientific concepts which are specific but at the same time might be generalized in the context of everyday life. The concern with the language shaped and used by quantum mechanics was externalized by their own creators. Given the problem of the relationship between the classical and the quantum languages, in this paper we argue that a way to deal with quantum phenomena is to keep the classical language but a different logic must be used, and so we are trying to locate this option from an epistemological point of view and show its implications for teaching.
\end{abstract}

Keywords: Language. Quantum mechanics. High School.

\footnotetext{
${ }^{1}$ Graduada em Física, doutora em Enseñanza de la Ciencia. Docente, Instituto de Física, Universidade Federal de Mato Grosso. Cuiabá, MT, Brasil.<ira@ufmt.br>

${ }^{2}$ Graduado em Física, doutor em Science Education. Docente, Instituto de Física, Universidade Federal do Rio Grande do Sul. Porto Alegre, RS, Brasil.<moreira@if.ufrgs.br>

${ }^{1}$ Av. Fernando Corrêa da Costa, n ${ }^{\circ} 2367$

Bairro Boa Esperança - Cuiabá, MT

$78.060-900$ 
Paulo, I. J. C.; Moreira, M. A.

\section{Introdução}

A questão da linguagem, entendida como o sistema articulado de signos no qual vivemos e com o qual nos comunicamos e construímos conhecimento, se apresenta com um ponto crucial na inserção da MQ (Mecânica Quântica) no nível médio, uma vez que é necessária a construção de novos termos (como onda-partícula e complementaridade), os quais não fazem parte do linguajar aprendido com os tópicos de Física tradicionalmente presentes nesse nível de ensino.

Essa questão pode ser assim colocada: segundo a Teoria da Aprendizagem Significativa (TAS) (MOREIRA, 2006), para atribuir significados a novos conhecimentos, o aprendiz parte de conceitos já estabelecidos em sua estrutura cognitiva, os chamados subsunçores. Desta forma, os subsunçores potencialmente utilizáveis na introdução da MQ seriam clássicos e formulados em linguagem clássica ${ }^{3}$. Como então utilizar subsunçores de uma teoria (Física Clássica) fundamentada em significados contrários aos da MQ?

Uma possível resposta a esse aparente paradoxo é dada pela própria Interpretação de Copenhagen ${ }^{4}$ :

A interpretação de Copenhagen da teoria quântica tem, como ponto de partida, um paradoxo. Qualquer experiência em Física, refira-se ela a eventos da vida comum ou eventos atômicos, tem que ser descrita na terminologia da Física Clássica. Os conceitos da Física Clássica propiciam a linguagem por meio da qual descrevemos os arranjos experimentais e enunciamos os seus resultados. (HEISENBERG, 1995, p. 39)

Ou seja, a dificuldade com relação à linguagem também foi crucial na própria construção da MQ enquanto nova área do conhecimento humano. Para lidar com essa dificuldade, Heisenberg (1995) sugeriu a manutenção da linguagem e a modificação da lógica. A linguagem clássica é o limite, embora a sua utilização leve a modificações em sua própria lógica. $\mathrm{O}$ objetivo deste trabalho é discutir essa posição e suas implicações para o ensino da MQ no nível médio.

\section{O problema da linguagem}

Os conceitos da Física Clássica (FC) foram construídos e modificados ao longo do tempo. Novas terminologias foram surgindo, adaptações da linguagem comum foram sendo feitas e o campo de conceitos foi se delineando e se expandindo. O Prêmio Nobel de Física de

\footnotetext{
${ }^{3}$ No contexto da TAS, o conhecimento prévio é a variável que mais influencia a aprendizagem. Normalmente, essa influência é facilitadora, mas há casos em que é inibidora, bloqueadora. O conhecimento prévio pode servir de obstáculo epistemológico, ou noção obstáculo, como diria Bachelard (1985).

${ }^{4}$ Nome dado à interpretação da MQ formulada por Niels Bohr, Werner Heisenberg e Max Born, principalmente.
} 
O problema da linguagem e o ensino da mecânica ...

1969, Murray Gell-Mann, é um bom exemplo de um cientista que contribuiu para a expansão da população conceitual da ciência pela criação de novos conceitos, como "quark" e "estranheza" (BRENNAN, 1998).

A linguagem é o meio que utilizamos para fazer, divulgar e utilizar ciência para dar conta das nossas relações com o mundo. Contudo, conforme a ciência avança, essa linguagem sofre modificações. O progresso da técnica experimental dos nossos tempos coloca, ao alcance da ciência, novos aspectos da natureza que não podem ser descritos na forma de conceitos da vida diária.

A exposição de resultados experimentais e conceitos científicos aos leigos pode se tornar efetiva se a explicação oferecida despertar a atenção dos mesmos, o que pode ser obtido em termos de uma linguagem, comum a todos, compreensível. Mas, mesmo para um físico, a capacidade de fazer uma exposição em linguagem simples se constituirá em um critério do grau de entendimento que ele chegou.

A linguagem envolve um grande número de conceitos que se mostram um instrumento conveniente para uma descrição mais ou menos precisa dos acontecimentos da vida cotidiana. Alguns conceitos vão sendo adquiridos aos poucos sem maior análise crítica, apenas pelo uso constante sem uma captação adequada de seus significados. Muitas vezes, após empregarmos muito frequentemente uma palavra, acreditamos saber o que ela significa.

Segundo Heisenberg (1995), a incerteza intrínseca presente no significado das palavras foi reconhecida desde muito e, em consequência, trouxe a necessidade de definições ou como indica a etimologia do termo definição - a delimitação do domínio de aplicabilidade das palavras utilizadas. As definições, todavia, não podem ser construídas, senão a partir de outros conceitos, de sorte que, em última instância, é necessário se ter por base conceitos ditos "primitivos" $"$, em que não cabem análises ou definições.

O autor defende a ideia de que vocábulos possam desencadear, em nossa mente, imagens numerosas e semiconscientes, que podem ser utilizadas para representar, na linguagem, partes da realidade de maneira muito mais clara do que as construções lógicas por si propiciam. Trata-se de uma posição conflitante com relação a Popper (1992), no que diz respeito à posição secundária atribuída às imagens e conceitos, pois, para ele, basta uma teoria, como um esquema lógico, sem se fazer menção a imagens visuais.

\section{Popper: as imagens não são imprescindíveis}

Um dos pontos fundamentais da epistemologia popperiana é a valorização da teoria científica. Tal valorização apresenta algumas implicações com relação ao ensino, na medida em que Popper (1992) outorga à teoria um status superior aos conceitos e imagens através dos quais ela é expressa:

${ }^{5}$ Poderiam corresponder aos primeiros subsunçores segundo a Teoria da Aprendizagem Significativa

(AUSUBEL, 2000), ou aos primitivos conceituais da Teoria dos Modelos Mentais de Johnson-Laird (1983). 
Paulo, I. J. C.; Moreira, M. A.

Uma teoria não é uma imagem. Uma teoria não precisa ser "compreendida" por meio de "imagens visuais": compreendemos uma teoria quando compreendemos o problema que esta se destina a resolver e a maneira como o resolve melhor ou pior do que as suas concorrentes. [...] Estas considerações são importantes devido às intermináveis discussões existentes sobre a "imagem de partícula" e a "imagem de uma onda" e da sua suposta "dualidade" ou "complementaridade" e sobre a pretensa necessidade, definida por Bohr, de se utilizar "imagens clássicas" por causa da dificuldade (admissível mas irrelevante) ou até talvez impossibilidade de se "visualizar" e, portanto, "compreender" os objetos atômicos. Mas este tipo de "compreensão" é de escassa importância. E a negação da possibilidade de se compreender a teoria dos quanta teve as repercussões mais tentadoras quer no ensino quer na verdadeira compreensão da teoria. De fato, toda esta discussão das imagens não tem a menor influência quer na física, ou nas teorias físicas, quer na compreensão destas. [...] Se os conceitos são relativamente pouco importantes, as definições necessariamente terão também de o ser. (POPPER, 1992, p. 62)

Como se pode perceber das palavras de Popper (1992), a atribuição de um status secundário a imagens e conceitos também se constitui em uma crítica à Interpretação de Copenhagen, na qual os conceitos e imagens humanos foram construídos classicamente, apresentando limitações na compreensão do mundo quântico. Consequentemente, pelo menos parte da "estranheza" do mundo quântico se deve às nossas limitações conceituais e imagísticas (HEISENBERG, 1995). Para Popper, ao contrário, tal argumentação parecia artificial, como uma "desculpa" dada pelos seguidores de Bohr, sendo que o que de fato estava por trás da "estranheza" quântica é a incompletude da MQ.

Assim, para Popper (1992, p. 62), é de importância secundária a utilização de imagens de objetos clássicos comuns ou fazer analogias clássicas: para uma teoria científica, as imagens e conceitos não têm importância fundamental. Aparentemente, para ele, uma teoria pode ter um caráter abstrato independente de imagens visuais e conceitos concretos. Ao se optar por seguir essa linha, particularmente no ensino da $\mathrm{MQ}$, dever-se-ia evitar as analogias clássicas. Percebe-se, portanto, que, nesse aspecto, do ponto de vista epistemológico, a opção popperiana é contrária à da Interpretação de Copenhagen.

\section{Interpretação de Copenhagen: a linguagem clássica é imprescidível}

Para a Interpretação de Copenhagen, a ciência está forçosamente baseada na linguagem como o seu único meio de comunicação. Nas ciências naturais, tenta-se, a partir do geral, deduzir o particular e, assim, entender um dado fenômeno como consequência de leis gerais que devem ser formuladas da maneira mais simples possível. As leis gerais, uma vez formuladas, em linguagem apropriada, conteriam um pequeno número de conceitos básicos; caso contrário, não seriam nem simples nem gerais. Transpondo isso para o processo de conceitua- 
O problema da linguagem e o ensino da mecânica ...

lização, é possível inferir que quanto maior o número de conceitos adquiridos por um aprendiz, maior o número de elos que podem ser feitos formando uma cadeia conceitual que pode ser utilizada para explicar um número crescente de fenômenos, ampliando, assim, o domínio do campo conceitual pertinente. Assim como ocorre no processo de evolução do conhecimento científico, no processo de aprendizagem ocorre uma expansão correspondente da terminologia que a linguagem ostenta. Novos termos são criados e os mais antigos ganham um maior domínio de aplicabilidade ou, então, tomam significados distintos do uso comum. É dessa maneira que se desenvolve não só a linguagem científica, academicamente falando, mas também a linguagem científica de um aprendiz (dimensão ontológica), ou seja, ambas se desenvolvem ou são encaradas como uma extensão natural da linguagem comum ou uma adaptação aos novos campos do conhecimento científico.

Conforme Heisenberg (1995, p. 132) conclui:

"é sempre difícil encontrar critérios fidedignos que indiquem quais e de que maneira termos linguísticos devam ser empregados. Aqui a solução é, por assim dizer, um compasso de espera a fim de que a evolução da linguagem venha, com o passar do tempo, a permitir um ajustamento à nova situação.”

Assim, por meio do processo de expansão da linguagem, parece ser possível partir-se de termos clássicos da FC, o que abre perspectivas para que a questão da linguagem não se apresente como um obstáculo intransponível. Contudo, há dificuldades consideráveis de linguagem na abordagem da teoria quântica. $\mathrm{Na} \mathrm{MQ}$ o problema da linguagem é complexo porque não se tem de começo nenhum critério simples para se correlacionarem os símbolos matemáticos aos símbolos da linguagem cotidiana. A única coisa que sabemos, como ponto de partida, é que os conceitos comuns não são aplicáveis ao estudo das estruturas atômicas. A abordagem mais óbvia para a interpretação física do formalismo parece ser o fato de que o esquema matemático da MQ tende ao da Mecânica Clássica (MC) para os sistemas físicos com dimensões apreciavelmente maiores que as exibidas pelos átomos.

$\mathrm{Na}$ interpretação de um experimento quântico, como, por exemplo, no caso do movimento do elétron em uma câmara de Wilson, através de técnicas experimentais, podemos determinar a posição e velocidade iniciais do elétron; sabemos que essa determinação não é precisa, fazem parte dela imprecisões provenientes da correspondente relação de incerteza e ainda, muito provavelmente, erros próprios das condições técnicas do experimento. Entretanto, essas imprecisões permitem traduzir os resultados da observação em uma linguagem matemática dentro do formalismo da teoria quântica através de uma função de probabilidade que representa o fenômeno no instante que a observação foi feita, inclusive os eventuais erros cometidos nas medidas. Assim, essa função de onda é a representação, em parte, de um fato e, em parte, daquilo que conhecemos desse fenômeno. Uma vez escrita a função de probabilidade de um determinado evento, no seu instante inicial, pode-se calcular, com o auxílio de leis, a função de probabilidade em qualquer instante futuro e, consequentemente, determinar a probabilidade de ocorrência, em uma medida, de um certo valor da grandeza observada. A função de probabilidade na MQ representa uma tendência para a ocorrência de eventos e nosso conhecimento acerca desses eventos. Ela está ligada à realidade à medida que consegue deter- 
minar, em uma outra situação, certa propriedade do sistema físico considerado. O resultado da medida, entretanto, é expresso em termos da FC. Nesta, por sua vez, através da Mecânica Newtoniana, pode-se, por exemplo, determinar a posição e velocidade de um planeta. O resultado da observação é traduzido em linguagem matemática com o auxílio de valores numéricos. Assim, as equações de movimento são utilizadas para que, partindo dos valores das coordenadas e momentos lineares em um dado instante de tempo, valores futuros possam ser estimados predizendo a ocorrência de novos fenômenos dentro de um sistema. Há que se considerar também que, mesmo em uma experiência cuidadosamente conduzida, os erros experimentais existem e, como resultado, em uma análise criteriosa, pode-se obter uma distribuição de probabilidade para os valores iniciais de posições e velocidades, algo muito semelhante à função de probabilidade da $\mathrm{MQ}$, com a diferença de que as incertezas vinculadas ao princípio de indeterminação estão ausentes na FC (HEISENBERG, 1995).

Os livros e o Ensino Médio tradicional da FC, entretanto, não fazem referência nem às incertezas de cunho experimental, o que exigiria uma abordagem probabilística dos fenômenos. Em defesa desse tipo de abordagem, pode-se argumentar que não há necessidade da introdução do aspecto probabilístico para a compreensão e utilização do conhecimento físico no cotidiano. Seria, portanto, uma abordagem desnecessária, uma vez que a FC que se aprende na escola atende aos anseios e necessidades de conhecimento acerca da natureza, mais próximos da realidade do educando.

Contudo, as incertezas estão presentes na sociedade contemporânea, e os jovens não estão sendo preparados para lidarem com suas dúvidas que são geradas, inclusive, pelo grande fluxo de informações, pelo anseio de compreender e utilizar novas tecnologias. O ensino da FC pode estar sendo um fator que reforça certezas, em um mundo cujos fenômenos têm características mais probabilísticas do que determinísticas. O universo determinístico reifica a concepção de que pouco pode ser feito para mudar o curso dos acontecimentos. Já o universo probabilístico oferece opções para a tomada de atitudes, pois existem caminhos alternativos para soluções desses problemas. Não defendemos aqui uma abordagem completamente probabilística para os fenômenos clássicos, mas, sim, que a abordagem probabilística pode constituir uma interface entre a FC e a MQ.

O sistema físico não poderia ser o objeto de investigações teóricas, não pertenceria ao mundo dos fenômenos se não tivesse interação alguma com as outras partes do sistema maior do qual faz parte o observador. No caso limite de amplas dimensões, esse elemento estatístico destrói os efeitos da interferência de probabilidades, e isso de tal maneira, que agora o esquema da MQ de fato tende ao clássico no limite considerado. Nesse ponto, portanto, a correlação entre os símbolos matemáticos da MQ e os conceitos da linguagem comum não exibe qualquer ambiguidade e ela se revela suficiente para a interpretação das experiências.

Em geral, os problemas remanescentes dizem respeito à linguagem ao invés de fatos, pois faz parte do conceito de "fato" ser ele passível de uma descrição na linguagem cotidiana.

Pode-se dizer que o conceito de complementaridade, introduzido por Bohr (1995), veio encorajar os físicos a utilizarem linguagem ambígua ao invés de uma desprovida de ambiguidades. Nesse caso, faz-se uso de conceitos clássicos distintos que, usados simultaneamente, podem, a princípio, levar a contradições, mas que estão relacionados a resultados experimentais e ao formalismo matemático, ou seja, não estão desvinculados de qualquer coisa.. Citando o próprio Bohr: 
O problema da linguagem e o ensino da mecânica ...

Por maiores que sejam os contrastes exibidos pelos fenômenos atômicos em diferentes condições experimentais, esses fenômenos devem ser chamados de complementares, no sentido de que cada um deles é bem definido, e de que, juntos, eles esgotam todo conhecimento definível sobre os objetos em questão. (BOHR, 1995, p. 114)

A questão aqui é o surgimento de um novo conceito que incorpora algumas características de conceitos clássicos com significado completamente novo (contudo, tais contradições acontecem dentro da lógica clássica, mas elas não seriam de fato contradições dentro de uma outra lógica). Continua Bohr: "longe de conter qualquer misticismo alheio ao espírito da ciência, a noção de complementaridade aponta para as condições lógicas da descrição e da compreensão da experiência na física atômica" (BOHR, 1995, p. 115).

Heisenberg (1995) nos chama a atenção que a complementaridade não se restringe ao mundo atômico, que ela permeia reflexões acerca de uma decisão a ser tomada, aos motivos de uma escolha, ou, como cita: "[...] quando quisermos escolher entre usufruir sensualmente da música ou analisar a sua estrutura" (p. 135).

De alguma maneira, devemos abordar, em sala de aula, algo mais que fatos acerca do fenômeno quântico: vamos extrapolar os sinais dos elétrons (gotículas de água) na câmara de Wilson ou as franjas de interferência em uma chapa fotográfica e, então, a linguagem torna-se um desafio evidente porque teremos de descrever a estrutura dos átomos no processo de conceitualização.

Segundo Heisenberg (1995), a linguagem utilizada até então para descrever o objeto ou evento quântico obedece a uma lógica que se diferencia da lógica clássica, pois esta se baseia no princípio do "terço excluído": se "uma afirmação tiver sentido, há então somente duas possibilidades a considerar, a saber, ela é correta ou caso contrário, sua negação o será" (p. 137).

Ou seja, não existe uma terceira possibilidade de verdade. É possível que não tenhamos conhecimento suficiente para fazer a escolha correta, mas uma e somente uma asserção seria verdadeira acerca do fenômeno/objeto considerado. Contudo, numa outra perspectiva lógica, pode-se considerar um continuum de possibilidades entre os dois extremos. Por exemplo, o estado quântico que caracteriza prótons, elétrons, nêutrons e fótons, corresponde aos aspectos ondulatórios e corpusculares simultaneamente, num continuum que vai desde o estado puramente ondulatório até o puramente corpuscular, dependendo da maneira como se dá a interação com os instrumentos de medida. Um outro exemplo se refere ao spin de prótons, elétrons e nêutrons: quando se faz com que esses férmions passem através de dois campos magnéticos homogêneos orientados em direções diferentes, defasados por um certo ângulo, o seu spin, após passar pelo primeiro campo, está parcialmente "para cima" e parcialmente "para baixo" em relação ao segundo campo, ou seja, o sentido do spin em relação a um campo magnético externo (que constitui o nosso instrumento de medida para "vê-lo") está num continuum de valores que combinam a orientação "para cima" com a orientação "para baixo". Esse é um outro exemplo de experimento em que duas características classicamente excludentes aparecem simultaneamente (COHEN-TANNOUDJI et al., 1977).

$\mathrm{Na} \mathrm{MQ}$, o princípio da complementaridade por si já invoca uma improbabilidade da utilização do princípio do terço excluído, a menos que, já adaptados a ele, optemos por uma 
eventual modificação em sua lógica. Isto pode ser feito distinguindo, segundo Weizsäcker (apud HEISENBERG, 1995), diversos níveis de linguagem, onde o primeiro se refere a objetos (átomos, elétrons), o segundo, a enunciados sobre objetos, e o terceiro, a respeito dos enunciados sobre enunciados acerca dos objetos e, assim, sucessivamente. Atribuindo-se, desta forma, modos lógicos distintos para cada nível. Fato é que, de qualquer forma, temos que retornar à linguagem comum, passando inevitavelmente pela FC.

Retomando a possibilidade de uma abordagem em sala de aula (em uma perspectiva ausubeliana), a base conceitual do conhecimento científico (ou subsunçores) está estruturada em experiências ou vivências que o aprendiz capta do mundo em redor, da realidade a qual se insere, permeada de uma linguagem coloquial, que muitas vezes reflete o senso comum muito mais ligado a conceitos da FC do que propriamente da Física Contemporânea na qual a MQ se insere. É bem verdade que alguns termos da MQ já são mais ou menos corriqueiros, e aqui caberia uma investigação em representações sociais desses alunos, que não é o caso, agora, mas podemos ousar inferir três hipóteses com relação a como se daria o processo de "extensão da linguagem" na introdução da MQ no nível médio (PAULO, 2006): 1) significados são captados, mas não são, de fato, compreendidos em seu sentido científico, uma vez que o aprendiz não é capaz de negociar este significado com o professor, ou melhor, o significado captado não é ainda aquele que o professor desejaria e que é aceito no contexto da matéria de ensino. Entretanto, o aprendiz pode utilizá-lo de forma relativamente satisfatória no seu cotidiano, no seu grupo de convívio social - é o que poderíamos chamar de significado social; 2) conceitos pertinentes à MQ são captados e compreendidos a partir dos conceitos clássicos já existentes na estrutura cognitiva do aprendiz, ou seja, subsunçores aos quais ele recorre e que ficam explicitados na linguagem utilizada para se expressar, por exemplo, o conceito de dualidade, onde a entidade quântica "ora se comporta como onda e ora se comporta como partícula". Então, fica explícita a captação do significado de que a dualidade onda-partícula não é uma simultaneidade, mas uma duplicidade comportamental, mantendo a lógica clássica. Normalmente, esse caso está correlacionado a uma pretensão pragmática na utilização da $\mathrm{MQ}$, como, por exemplo, nas suas aplicações tecnológicas; 3) significados são captados e compreendidos, mas não se mantém a lógica clássica, e adota-se uma lógica mais condizente com a MQ. Nesse caso, o aluno é capaz de trocar significados com o professor, mas no âmbito de uma lógica não clássica, que é o ponto objetivado pelo professor e que é condizente com o contexto da matéria de ensino, compartilhado com a comunidade científica. Este seria o caso ideal de uma aprendizagem significativa crítica (MOREIRA, 2005) em relação à Interpretação de Copenhagen.

\section{Bachelard: a lógica clássica é prescindível}

A ruptura com a lógica clássica corresponde a uma das ênfases da epistemologia bachelardiana. O grande motivador que levou Bachelard a escrever duas de suas principais publicações (A formação do espirito científico e $O$ novo espirito científico) foi o advento da Física Moderna (Mecânica Quântica e Relatividade). Para Bachelard (1985), o novo espírito científico seria implantado com a compreensão da Física Moderna. Para isso, ele defende o ponto de vista de que o indivíduo deve procurar romper as suas convicções mais arraigadas, buscando, continuamente, reformular o seu ponto de vista. 
O problema da linguagem e o ensino da mecânica ...

Em O novo espirito científico, Bachelard defende explicitamente a ruptura com o pensamento cartesiano (clássico) em prol da implementação de um pensamento não clássico:

Não há, portanto, transição entre o sistema de Newton e o sistema de Einstein. Não se vai do primeiro ao segundo acumulando conhecimentos, redobrando os cuidados nas medidas, retificando ligeiramente os princípios. É preciso, ao contrário, um esforço de novidade total. Segue-se, pois, uma indução transcendente e não uma indução amplificante, indo do pensamento clássico ao pensamento relativista. Naturalmente, após esta indução pode-se, por redução, obter a ciência newtoniana. A astronomia de Newton é, pois, finalmente um caso particular da Pan-astronomia de Einstein. (BACHELARD, 1985, p. 44)

Assim, ao se levarem em conta as considerações bachelardianas para a introdução de tópicos de Física Moderna e Contemporânea no Ensino de Nível Médio, a lógica científica subjacente à Física Clássica deve ser rompida e abandonada. Caberia, então, ao professor do Ensino Médio, promover uma visão não clássica de toda a ciência? O que seria uma tarefa relativamente difícil de ser obtida, dada a formação basicamente clássica desses profissionais. Não bastaria, pois, para Bachelard, a simples introdução de tópicos de Física Moderna no Ensino Médio, mas a modificação de toda uma postura e percepção de mundo.

Desse ponto de vista, a epistemologia bachelardiana é coerente com a postura da Interpretação de Copenhagen a respeito da utilização de uma nova lógica. Contudo, a manutenção da linguagem clássica, defendida nessa interpretação, deve ser feita com um certo cuidado, não podendo ser levada ao extremo, pois, de acordo com Bachelard (1985), poderia se tornar um obstáculo epistemológico verbal. Segundo esse epistemólogo, a história da ciência mostra que, por vezes, uma palavra adquire tal peso numa teoria ou conjunto de ideias que deturpa e impede o desenvolvimento da ciência. A utilização de certas palavras de maneira sobrevalorizada resulta no aparecimento de "hábitos de natureza verbal", ou seja, termos mal colocados que extrapolam seu próprio âmbito de validade (BACHELARD, 1985, p. 91).

Como exemplo desse obstáculo, Bachelard (1985) apresenta a palavra "esponja”, que foi utilizada indevidamente em diversas ocasiões na história da ciência, como no ano de 1731, quando Réaumur propõe que o ar é como uma esponja (BACHELARD, 1985, p. 92) e, então, a umidade do ar pode ser explicada porque o ar pode "sugar" a água. É claro que esse tipo de modelo incorre numa incoerência fundamental: a água, no ar, não está em estado líquido. Segundo Bachelard (1985), tal obstáculo acontece devido a um apego a palavras específicas. Assim, analogias são estabelecidas além de qualquer limite. Tudo fica facilmente explicado: o ar é uma esponja, o pulmão é uma esponja, assim como a pele, a terra, etc., evitando, desta forma, o penoso processo de reflexão crítica.

Verifica-se, portanto, que Bachelard (1985) é coerente com a ruptura com a lógica clássica, todavia, como foi dito, é necessário muito cuidado com a utilização da linguagem clássica para não se incorrer em obstáculos de natureza verbal, até porque isso pode implicar em uma aprendizagem significativa diversa da conceitualização compartilhada pela comunidade científica. Aprendizagem significativa não é sinônimo de aprendizagem correta (no sentido de cientificamente compartilhada). 
Paulo, I. J. C.; Moreira, M. A.

\section{Um paradoxo da MQ: a linguagem clássica, a lógica quântica e implicações para o ensino}

O problema da verbalização ou da linguagem, tanto na compreensão como no ensino da Mecânica Quântica, é de particular importância, pois, dado o grau de abstração dos conceitos, há um risco considerável de que sejam deturpados em função de uma palavra ou frase mal colocada. O mundo ou domínio atômico parece apresentar-se como uma junção (ou acoplamento) de concepções contrárias. Percebe-se isso, muito bem, na relação de incerteza de Heisenberg, traduzida na forma de uma desigualdade matemática. Ao designar a posição de uma partícula pela variável $\mathbf{q}$ e a quantidade de movimento pela variável $\mathbf{p}$, as incertezas de cada uma delas (Dq e Dp) estão relacionadas por:

$$
\Delta q \Delta p>\frac{\hbar}{2}
$$

no qual h é a constante de Planck, $\mathbf{h}$, dividida por $2 \pi$. Esta é, portanto, uma maneira frequente de se expor a relação entre a precisão das medidas de posição e de velocidade ou momento cinético. Entretanto, é possível, por analogia, estender esta relação de incerteza para outras variáveis, tais como tempo e energia, ou, ainda, a outras, num aspecto todo matemático em que os parâmetros conceituais perderam já a intuitividade.

Parece-nos, então, que o princípio de incerteza constitui um novo caminho para se pensar o fenômeno microfísico em seus aspectos duais: corpuscular e ondulatório. Trata-se, portanto, da junção de concepções conceituais antagônicas, e temos, aí, um problema de conceitualização onde, a partir do real, deve-se descrever o imaginário. Fenômenos microfísicos são descritos a partir de observações de seus "sinais", e não da observação experimental direta.

Mesmo que o princípio de incerteza parta da concepção de que não se devam utilizar grandezas que não são efetivamente mensuráveis, sabemos que os aspectos ondulatórios e corpusculares não podem ser medidos simultaneamente. Para "realizar" ou tornar real o conceito de dualidade, não basta um traço de junção ou o acréscimo da preposição "e" entre os dois adjetivos, formando o termo "onda-partícula" ou "onda e partícula". Instaura-se, aqui, um problema de conceitualização na Física Quântica que, até nos dias atuais, não está resolvido. Não há consenso sobre qual é o melhor termo para descrever ou caracterizar a entidade quântica. Ou seja, empregamos palavras que definem o mundo macroscópico num âmbito microscópico.

Os conceitos de onda e de partícula têm caráter universal distinto para descrever o mundo clássico, que contempla fenômenos que estamos acostumados a observar e interagir no mundo perceptível, de onde tiramos informações a partir das quais construímos nossos conceitos.

Entretanto, a partir de Heisenberg (1995) e seu princípio, temos uma proposta de transpor o real - o palpável para o "real-imaginário" - e sentimos, por isso, as limitações das atribuições realistas da linguagem e, ao mesmo tempo, a importância das imagens na compreensão do mundo quântico, em posição não condizente com a epistemologia popperiana.

Um caminho possível para melhorar a transição entre a lógica clássica e a lógica quântica através da linguagem pode ser buscado na própria teoria quântica, quando Weizsäcker introduz o conceito de "grau de verdade" (apud HEISENBERG, 1995, p. 138), refe- 
O problema da linguagem e o ensino da mecânica ...

rindo-se ao fato de que, na MQ, em concordância com o princípio de complementaridade, algo pode ter, ao mesmo tempo, um certo grau de uma dada característica e um grau complementar da característica oposta, como, por exemplo, no experimento imaginário do gato de Schrödinger: antes da observação direta, o gato pode estar, digamos, $70 \%$ vivo e $30 \%$ morto, dependendo do estado do sistema, o qual é definido por fatores tais como o tempo de observação e o tipo de elemento radioativo utilizado no experimento. Da mesma forma, em determinadas circunstâncias, é adequado se interpretar uma entidade quântica mais como onda de matéria e menos como partícula, como, por exemplo, as ondas estacionárias de matéria ao redor do núcleo atômico. Ao se lidar com a radiação emitida pelo átomo, é mais conveniente o uso de ondas de matéria, conforme Heisenberg: "Por intermédio de suas frequências e intensidades, a radiação presta informação acerca da distribuição de carga oscilante no átomo e, nesse caso, a descrição ondulatória aproxima-se muito mais da verdade do que a de partículas" (1995, p. 42). Já no caso da emissão de radioatividade pelo núcleo, é mais conveniente a utilização da descrição em termos de partículas.

Não sabemos se "qualquer" experiência "tem" que ser escrita na terminologia clássica. Pensamos ser importante a analogia com a FC, desde que esta seja reinterpretada dentro de uma outra perspectiva (ou lógica), até para a criação de novas terminologias.

Conforme salientado por Niels Bohr (apud HEISENBERG, 1996), a ciência não é somente a observação de fenômenos (que são descritos por leis diferentes das da FC), mas também a comunicação de resultados a terceiros (que deve ser feita em termos da linguagem clássica). Tem-se, então, também um paradoxo instaurado no âmbito do ensino da MQ: de um lado, fenômenos quânticos diferem dos clássicos; por outro lado, sua comunicação se faz sem nenhuma reserva a partir da linguagem clássica, de significados clássicos. No ato de ensinar, parece que não há como fugir disso, pois somos obrigados a usar a linguagem que tem a mesma estrutura daquela que falamos na experiência cotidiana. Evidentemente, tal linguagem é um meio de comunicação e orientação que pode resultar inadequada, porque pode gerar imagens e representações alternativas, mas é a única disponível.

Por outro lado, embora o aluno parta de uma linguagem clássica, conforme adentra na teoria quântica, é possível a progressiva apropriação de novos termos, oriundos de uma nova lógica e, assim, seu campo conceitual vai se ampliando.

Partindo de qualquer uma das hipóteses aventadas acima, parece-nos que a linguagem é um reflexo da extensão do domínio conceitual alcançado pelo aprendiz.

Não é possível estabelecer uma relação de ensino-aprendizagem de uma ciência sem compreender os significados que a própria ciência atribui aos seus objetos de estudo. Logo, o problema da linguagem no ensino da MQ deve-se, em parte, à dificuldade da compreensão dos fenômenos quânticos, uma vez que essa área do conhecimento resultou em novos conceitos até certo ponto distantes da percepção humana. Tais conceitos envolvem uma dimensão diferenciada daquela referente aos conceitos clássicos. Mas como se poderiam abordar os princípios quânticos sem fazer referência aos conceitos clássicos, inerentes à linguagem, uma vez que construir o conhecimento quântico "do zero" demandaria um tempo e uma linguagem não disponíveis na estrutura de ensino vigente? Por outro lado, poder-se-ia não usar imagens clássicas, como sugere Popper (1992). 


\section{Optando pela Interpretação de Copenhagen}

Existem várias interpretações conceituais e filosóficas da MQ (LALOE, 2001). Dessas várias interpretações, duas são consideradas, na literatura, por alguns autores, as mais importantes: a determinista ou causal de De Broglie-Bohm e a de Bohr (HOLLAND, 1993). Contudo, caso o professor opte pela Interpretação de Copenhagen-Bohr, qual seria a estratégia a ser adotada em sala de aula? Diante do que foi discorrido neste trabalho, o professor deve, de alguma forma, valorizar a linguagem clássica e os conceitos previamente construídos pelos aprendizes - o que pode ser feito adotando-se, por exemplo, os princípios da Teoria da Aprendizagem Significativa Crítica - TASC (MOREIRA, 2005; PAULO, 2006) - cuidando para que as analogias clássicas não ultrapassem o seu âmbito de validade. Porém, isso somente pode ser implementado utilizando-se uma lógica diferenciada, que admita, por exemplo, a coexistência de aspectos classicamente antagônicos e a incerteza como um elemento inerente à natureza e ao conhecimento humano.

A sugestão da Interpretação de Copenhagen de se manter a linguagem clássica indica que a definição dos conceitos básicos pode ser mantida, ou seja, os conceitos de posição, velocidade, quantidade de movimento, massa e energia, por exemplo, podem ser mantidos no ensino da MQ. Isso possibilita que a abordagem dessa área de conhecimento possa ser feita, desde o seu início, de maneira potencialmente significativa, uma vez que os novos conceitos podem ser construídos tomando-se os conceitos clássicos como subsunçores. De fato, a definição básica dos conceitos utilizados como exemplos acima não se modifica na $\mathrm{MQ}$, embora seu significado se altere, sobretudo, no que diz respeito às suas relações com outros conceitos. É preciso, no entanto, sempre ter em conta que os subsunçores podem também ser bloqueadores de novas aprendizagens.

Sabe-se que a Mecânica Quântica é muito diferente da Clássica. Mas, na Interpretação de Copenhagen, essa diferença estaria centrada na lógica. Embora o conceito de posição, por exemplo, se mantenha na MQ, nem sempre a posição de uma onda-partícula é bem definida. Um outro exemplo importante se refere ao conceito de trajetória. Embora a definição do conceito na MC e MQ seja o mesmo, na MQ tal conceito deve ser abandonado, porque não mais há sentido em se falar em trajetória no âmbito quântico (uma discussão aprofundada sobre isso pode ser obtida em Prigogine, 1996). Esse fato nos remete a um dos princípios fundamentais da TASC: o Princípio da Desaprendizagem (MOREIRA, 2005), já que a dinâmica dos objetos microscópicos segue uma lógica diferente. Segundo esse princípio, que é fundamental para a Aprendizagem Significativa Crítica, quando o conhecimento prévio se constitui em um fator impeditivo para a captação de novos significados, se faz necessária uma desaprendizagem, entendida aqui como a não-utilização do conhecimento prévio como apoio. Até porque uma vez que um conhecimento foi aprendido significativamente, não é mais possível "substituí-lo", ou, até mesmo, "livrar-se" dele, trata-se, então, de não utilizá-lo como subsunçor. O que, por vezes, pode não ser uma tarefa fácil, por dois motivos: primeiro, pela natureza dos conhecimentos da Mecânica Quântica, e, segundo, porque, para a aprendizagem significativa, o conhecimento prévio é a variável mais importante que influencia a aprendizagem do novo conhecimento.

A opção pela Interpretação de Copenhagen, contudo, pode não se constituir no único caminho frutífero para o ensino da MQ. Não se pode negar que outros caminhos sejam pos- 
O problema da linguagem e o ensino da mecânica ...

síveis. O tema é complexo, uma vez que, qualquer que seja a postura adotada pelo professor, é necessário ter consciência de que o ensino desse ramo do conhecimento humano envolve lidar com paradoxos, tanto do ponto de vista da MQ em si - já que estamos tentando compreender o mundo quântico sem a possibilidade de abandonar totalmente nossos preceitos clássicos - como do ponto de vista do ensino em si - já que subsunçores são necessários para a Aprendizagem Significativa, sendo que talvez tenhamos que abandonar uma série deles, pelo Princípio da Desaprendizagem, para diminuir nossas limitações quanto à captação dos significados do mundo quântico.

\section{Conclusão}

A linguagem constitui um aspecto fundamental para a troca de significados entre os atores envolvidos no processo ensino-aprendizagem, e, por sua vez, é fundamental para que ocorra aprendizagem significativa, particularmente quando se trata do ensino de um novo corpo de conhecimentos, como o da MQ. A Interpretação de Copenhagen tem uma clara posição com relação a essa questão: a manutenção da linguagem clássica com a condição de se abrir mão da lógica à qual estamos acostumados. Observa-se que essa opção corresponde a uma posição epistemológica definida e contrária (nesse aspecto) ao quadro estabelecido por Karl Popper. É importante ressaltar que a adoção da linguagem clássica deve ser feita com cuidado, evitando-se incorrer em excessos que representariam obstáculos de natureza verbal, conforme Bachelard (1985). A condição pela manutenção da linguagem clássica deve ser a adoção de uma lógica diferenciada daquela que utilizamos no cotidiano, ponto esse que talvez seja o mais difícil para o professor em sala de aula.

A abordagem determinística da FC, nessa óptica, constitui um problema porque incorre em uma visão de mundo também determinística. Um caminho possível seria a discussão do conceito de probabilidade, evidenciando a incerteza inerente dos fenômenos naturais. A caracterização do mundo microscópico é permeada por aspectos antagônicos e os fenômenos quânticos são probabilísticos; portanto, se a linguagem clássica é imprescindível para a compreensão dos mesmos, a lógica clássica já não é suficiente para essa compreensão.

Há diferenças sutis entre os conceitos clássicos e quânticos, no que se refere à linguagem, portanto, promover a aprendizagem significativa de tais conceitos é uma tarefa desafiadora, tendo em vista que a captação de significados resulta de uma negociação de significados via linguagem clássica que, por vezes, implica o abandono da lógica clássica. Não se pode vislumbrar que isso ocorra sem, por vezes, promover a desaprendizagem de conhecimentos prévios. 
Paulo, I. J. C.; Moreira, M. A.

\section{Referências}

AUSUBEL, D. The acquisition and retention of knowledge: a cognitive view. Dordrecht: Kluver Academic Publishers, 2000.

BACHELAR, G. O novo espírito científico. Rio de Janeiro: Tempo Brasileiro, 1985.

BOHR, N. Física atômica e o conhecimento humano: ensaios 1932-1957. Rio de Janeiro: Contraponto, 1995.

BRENANN, R. Gigantes da física. Rio de Janeiro: Jorge Zahar, 1998.

COHEN-TANNOUDJI, C.; DIU, B.; LALOE, F. Quantum mechanics. Paris: Hermann, 1977.

HEISENBERG, W. Física e filosofia. 3. ed. Brasília: UnB, 1995.

A parte e o todo. Rio de Janeiro: Contraponto, 1996.

HOLLAND, P. H. The quantum theory of motion: an account of the de Broglie-Bohm causal interpretation of quantum mechanics. Cambridge: Cambridge University Press, 1993.

JOHNSON-LAIRD, P. Mental models. Cambridge: Harvard University Press, 1983.

LALOE, F. Do we really understand quantum mechanics?: strange correlations, paradoxes, and theorems. American Journal of Physics, s.l., v. 69, n. 6, p. 655-701, 2001.

MOREIRA, M. A. Aprendizagem significativa crítica. Porto Alegre: Instituto de Física, UFRGS, 2005.

. Teoria da aprendizagem significativa e sua implementação em sala de aula. Brasília: UnB, 2006.

PAULO, I. J. C. A aprendizagem significativa crítica de conceitos da mecânica quântica segundo a interpretação de Copenhagen e o problema da diversidade de propostas de inserção da física moderna e contemporânea no ensino médio. 2006. 235f. Tese (Doutorado en Enseñanza de las Ciencias) - Universidade de Burgos, Burgos, 2006.

POPPER, K. A teoria dos quanta e o cisma na física. 2. ed. Lisboa: D. Quixote, 1992.

PRIGOGINE, I. O fim das certezas. São Paulo: Editora Unesp, 1996.

Artigo recebido em dezembro de 2009 e aceito em abril de 2010. 